\title{
THE INFLUENCE OF ANTITOXIN UPON THE ACTION OF CLOSTRIDIUM OEDEMATIENS TOXIN IN THE HEART- LUNG PREPARATION OF THE DOG ${ }^{1,2,3}$
}

\author{
BY OTTO KRAYER, JOSEPH C. AUB, IRA T. NATHANSON, AND \\ PAUL C. ZAMECNIK
}

\begin{abstract}
(From the Department of Pharmacology, Harvard Medical School; and the Medical Laboratories of the Collis P. Huntington Memorial Hospital of Harvard University at the Massachusetts General Hospital, Boston, Mass.)
\end{abstract}

(Received for publication September 25, 1946)

Previous experiments (1) have indicated that $\mathrm{Cl}$. oedematiens toxin produces types of dynamic effects similar to those seen in traumatic shock. Blood volume was not diminished to the same extent as in hemorrhagic shock, but the peripheral vascular resistance rose and the cardiac output was reduced in the characteristic manner. It was not obvious, in the intact dog, whether these difficulties arose in the peripheral circulation or in the heart. Wiggers (2) has discussed a similar type of problem with reference to shock. Thus, in order to evaluate more specifically the factors involved in the circulatory failure resulting from $\mathrm{Cl}$. oedematiens toxin, the heart-lung preparation has been utilized.

\section{METHODS}

The experiments were carried out on the isolated heart and lungs of the dog in the form of the heart-lung preparation as described by Patterson and Starling (3). Mongrel dogs were used in all experiments and weighed between 7.8 and $11.3 \mathrm{kgm}$. They were anesthetized for the surgical procedure with sodium pentobarbital in a dose of $35 \mathrm{mgm}$. per $\mathrm{kgm}$. body weight. The period of preparation was timed so as to be about of equal duration in all experiments and was approximately 1 hour from the time of the first skin incision to the start of recording. The blood temperature varied in the various experiments not more than between 37 and $39^{\circ} \mathrm{C}$. and in the same experiment not more than $\pm 1^{\circ} \mathrm{C}$. The method of recording right auricular pressure, pulmonary pressure, and output is described in detail by Krayer and Mendez (4). In the

\footnotetext{
1 This is publication No. 632 of the Cancer Commission of Harvard University, and No. $X$ in the series entitled "The Toxic Factors in Experimental Traumatic Shock."

2 The work described in this paper was done under a contract, recommended by the Committee on Medical Research, between the Office of Scientific Research and Development and the Massachusetts General Hospital.

${ }^{3}$ Grateful acknowledgment is due the Josiah Macy, Jr. Foundation for a grant for the histopathological studies.
}

various experiments arterial resistance was between 75 and $85 \mathrm{~mm}$. $\mathrm{Hg}$, assuring a mean aortic pressure of about $100 \mathrm{~mm}$. Hg when the systemic output under basal conditions of blood supply was kept between 400 and $500 \mathrm{ml}$. (systemic output is output of left ventricle minus coronary flow). The competence of the heart was tested by increasing venous blood supply. This was achieved by raising the level of the blood in the venous reservoir in two steps of $50 \mathrm{~mm}$. each as described in detail by Krayer (5). In the normal heart, at the beginning of the experiment, this led to an increase of systemic output of 40 to 50 per cent of the basal value at the first step, and of 80 to 95 per cent of the basal value at the second step. While the main increase in the work of the heart thus represented an increase in volume work, a certain amount of increase in pressure work was also involved in this competence test, as the arterial resistance was not changed throughout the experiment; and the mean blood pressure, therefore, increased somewhat with an increase in systemic output; likewise pulmonary arterial pressure increased. The increase of pulmonary pressure in experiments of this type becomes more and more pronounced as anatomical changes begin to appear and eventually lead to lung edema. In the present series of experiments, competence tests were made at intervals of approximately 30 minutes until the limit of competence was reached. By definition we consider this to be the case when an increase in venous supply by raising the level of blood in the venous reservoir by $50 \mathrm{~mm}$. no longer leads to an increase in systemic output (5).

Defibrinated blood, taken from a bleeder dog, was used to fill the heart-lung system. The total blood volume usually amounted to 800 to $900 \mathrm{ml}$. at the beginning of the experiments.

Hematocrit determinations were done by taking $10 \mathrm{ml}$. of defibrinated blood from the heart-lung system and subjecting the blood to centrifugation at 2,400 revolutions per minute for 15 minutes.

Artificial respiration was carried out with the Starling respiratory pump, using room air; the stroke volume was kept between 125 and $150 \mathrm{ml}$., and the rate of ventilation was between 14 and 18 per minute.

Twenty-one experiments were conducted, in 16 of which $\mathrm{Cl}$. oedematiens toxin was administered. This was given into the blood stream before it entered the venous reservoir, to ensure good mixing with the blood before it 
reached the heart. The dose was 10 or $20 \mathrm{mgm}$. of $\mathrm{Cl}$. oedematiens toxin preparation $(45 \mathrm{~N}), 2,500$ mouse subcutaneous MLD per mgm., or $100 \mathrm{mgm}$. Cl. oedematiens toxin (N313), 500 mouse subcutaneous MLD per mgm.4 The material was dissolved prior to the administration in $10 \mathrm{ml}$. of 0.9 per cent sodium chloride solution and/or in phosphate buffer of $\mathrm{pH} 7.4$. The administration of the toxin was made at the basal inflow level and within a period of about 1 minute. Histamine content of the 2 toxin samples was checked with the use of isolated strips of guinea pig's ileum. The highest concentration tested was $1: 15,000$. The rise in tone of the gut was not characteristic and was very much less than that due to histamine dihydrochloride 1:60 million.

The antitoxin was a polyvalent preparation (Lederle). It was given in a dose of $7 \mathrm{ml}$. in 8 experiments and was administered within approximately 30 seconds.

Dogs in 3 experiments were actively immunized against $\mathrm{Cl}$. oedematiens toxin according to technics described in detail elsewhere (6). In one of the experiments (Experiment No. 7) the bleeder dog as well as the dog used for the heart-lung preparation was actively immunized, and no antitoxin administered during the course of the experiment. The immunization was carried out as follows: the bleeder dog was immunized with four 1-ml. subcutaneous injections of $\mathrm{Cl}$. oedematiens toxoid (Lederle No. $100 \times 18 \mathrm{~A}$ ), injections being given at 3 -week intervals. The heart-lung preparation dog (H.L.P.) was immunized similarly, with the exception that injections were given at weekly intervals. In Experiment No. 16 the H.L.P. dog was immunized. The bulk of the immunized blood was removed, $500 \mathrm{ml}$. of blood from a normal dog was then given into the H.L.P. and again removed to the greatest extent ("washout"), and fresh blood from a normal dog was then added to carry out the experiment. In Experiment 17, the H.L.P. dog was a normal animal. The normal blood was removed and the "immunized" blood from the H.L.P. dog of Experiment 16, together with the "washout," was used to carry out the experiment. The H.L.P. dog of Experiment 16 was immunized with $\mathrm{Cl}$. oedematiens toxoid (Novyi, No. $101 \times 18 \mathrm{~A}$, Lederle Laboratories). The dog was given 9 subcutaneous injections of $1 \mathrm{ml}$. of this toxoid at weekly intervals. In addition it received a dose of 1,250 MLD $\mathrm{Cl}$. oedematiens toxin per $\mathrm{kgm}$. intramuscularly, as a booster dose, a week before it was used for the heart-lung preparation.

Five experiments within this series were carried out as controls, using the identical procedure of preparation and testing of competence, but without administering either antitoxin or toxin.

At the end of several experiments, specimens of heart and of lung tissue were taken for pathological studies. They were fixed in Zenker's fluid and were stained with phloxine-methylene blue.

\footnotetext{
4 The authors are indebted to Professor Milan A. Logan, University of Cincinnati, for generous supplies of $\mathrm{Cl}$. oedematiens toxin.
}

\section{The action of toxin}

(All the results are given in Figure 1.) When toxin was added to the blood of the heart-lung preparation, no noticeable change in right auricular, pulmonary pressure, or competence occurred for a period of 30 to 50 minutes. After this, within a period of a quarter of an hour, pulmonary pressure increased and simultaneously the lungs became more rigid, indicating the onset of lung edema. In 3 experiments (Experiments 1, 2, and 3) with a dose of 10,20 , and $20 \mathrm{mgm}$. of $45 \mathrm{~N}$ toxin respectively, severe lung edema terminated the experiment within 65 to 75 minutes after the addition of the toxin. In Experiments 18 and 19, after the addition of $100 \mathrm{mgm}$. of $\mathrm{Cl}$. oedematiens toxin N313, severe lung edema terminated the experiment after 51 and 52 minutes respectively. No test of competence was performed in Experiment 19 after the administration of the toxin. As can be seen from Figure 1, heart-lung preparations made in the same way but not under the influence of toxin have a long survival time. Five control experiments (Nos. 13, 14, 15, 20, and 21) are plotted in the graph, so that the time 30 minutes after starting the recording arbitrarily was called zero time ( since the time between the start of recording and addition of toxin in all the toxin experiments in Figure 1 averaged approximately 30 minutes). In 4 control experiments $(13,14,15$, and 20) it took between 140 and 165 minutes to reach the limit of competence; in Experiment 21, it took 210 minutes. The limit of competence was used as an end point, since, as a rule, lung edema does not terminate a heart-lung preparation before the end of 3 hours or more. Signs of marked lung edema were present only in Experiment 15.

\section{The influence of antitoxin upon the toxin action}

In the 3 experiments with $10 \mathrm{mgm}$. of toxin $45 \mathrm{~N}$ and antitoxin (Experiments 4, 5, and 6 of Figure 1), the antitoxin was administered at varying intervals : 73 and 10 minutes before, and 17 minutes after the toxin. In all 3 cases the limit of competence was reached within 142 to 160 minutes, a period of survival significantly longer than in the experiments without antitoxin. Signs of lung edema were marked in Experiment 4. In Experiment 12 , in which antitoxin was given 10 minutes 


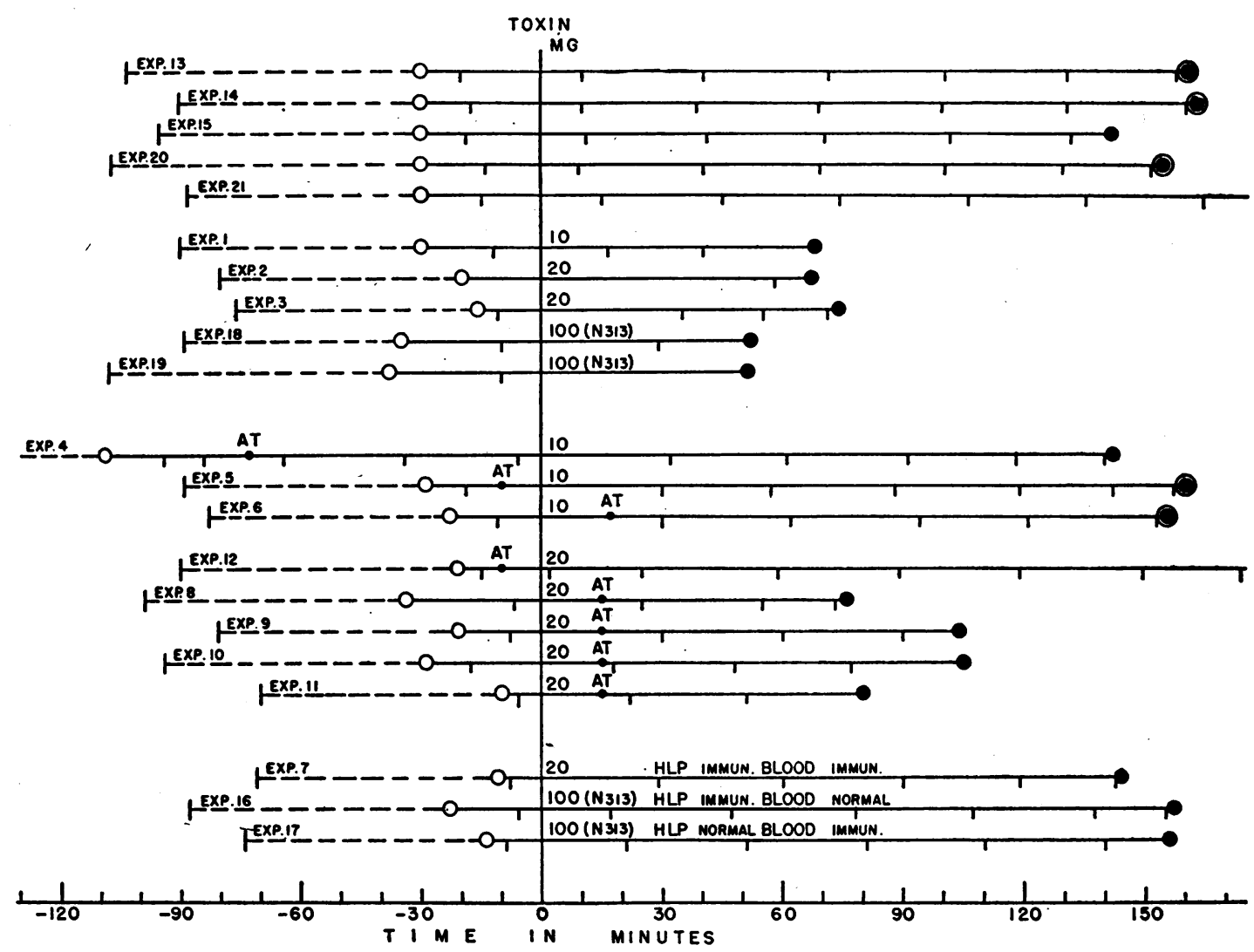

Fig. 1. The Action of Clostridium oedematiens Toxin upon the Heart-lung Preparation of the Dog

The dotted line from the vertical bar to the open circle indicates the time of preparation from skin incision to start of recording. The large full circle at the end of every horizontal line indicates lung edema. Limit of competence reached without marked signs of lung edema is indicated by the full circle placed in an open circle. The small full circle at the letters AT indicates administration of antitoxin. The figures 10 , 20 , and 100 respectively at the vertical zero time line indicate the administration of 10 or $20 \mathrm{mgm}$. of toxin $(45 \mathrm{~N})$ or $100 \mathrm{mgm}$. of toxin (N313). The signals below every horizontal line indicate the beginning of a competence test. For further information, see text.

prior to the dose of $20 \mathrm{mgm}$. toxin $45 \mathrm{~N}$, the limit of competence was reached only after 200 minutes. On the other hand, in the 4 experiments, $8,9,10$, and 11 , in which antitoxin was given 15 minutes after $20 \mathrm{mgm}$. of toxin $45 \mathrm{~N}$, severe lung edema occurred within 76, 80, 104, and 105 minutes respectively.

\section{Pathological changes}

The microscopic sections of the lungs, in preparation injected with toxin alone, revealed the presence of engorged pulmonary capillaries, and red cells and protein within the pulmonary alveoli. Where antitoxin was given prior to the toxin, the lungs at termination of the experiment (except in Experiment 4) showed either an absence of these findings or their presence to a minor degree. In all cases, the heart on microscopic examination showed no characteristic pathological changes.

\section{The influence of active immunization}

An attempt was made to obtain information on the effect of active immunization upon the response of the heart-lung preparation to toxin (Experiments 7, 16, 17 [Figure 1]). Although 2 different samples of toxin were used, the potency was identical in all 3 experiments $(50,000$ MLD mouse units). A definite inhibiting effect of immunization to the toxin action was observed not only when the blood as well as the heart and lungs were taken from immunized dogs (Experiment 7) but also when either the H.L.P. (Experi- 
ment 16) or the blood (Experiment 17) was from an actively immunized dog.

The alterations of the hematocrit in the heartlung preparation with respect to administration of Cl. oedematiens toxin are tabulated in Table I. The available data suggest that the hematocrit is not a good index of the onset of the pulmonary changes, probably because whole blood as well as plasma is lost into the pulmonary alveoli.

TABLE I

Relationship of hematocrit to administration of Cl. oedematiens toxin, in the heart-lung preparation

\begin{tabular}{c|c|l|c|c}
\hline \hline \multirow{2}{*}{$\begin{array}{c}\text { Dog } \\
\text { no. }\end{array}$} & $\begin{array}{c}\text { Dose of } \\
\text { toxin in } \\
\text { mouse } \\
\text { MLD }\end{array}$ & \multicolumn{1}{|c|}{$\begin{array}{c}\text { Time antitoxin } \\
\text { given }\end{array}$} & \multicolumn{2}{|c}{ Hematocrit } \\
\cline { 4 - 5 } & Original & Terminal \\
\hline 4 & 25,000 & $\begin{array}{l}72 \text { min. before toxin } \\
5\end{array}$ & 50 & 41 \\
6 & 25,000 & 10 min. before toxin & 50 & 58 \\
$7^{*}$ & 50,000 & none given & 41 & 68 \\
$16^{*}$ & 50,000 & none given & 54 & 47 \\
$17^{* *}$ & 50,000 & none given & 64 & 70 \\
8 & 50,000 & 15 min. after toxin & 65 & 69 \\
9 & 50,000 & 15 min. after toxin & 59 & 59 \\
18 & 50,000 & none given & 46 & 74 \\
19 & 50,000 & none given & 48 & 61 \\
\hline
\end{tabular}

* Immunized dog.

** Blood from immunized dog used.

\section{DISCUSSION}

Under the conditions of our experiments, the action of $\mathrm{Cl}$. oedematiens toxin is essentially on the pulmonary vessels, producing changes which lead to loss of blood into the lungs. While it cannot be said that the heart muscle is not affected, changes in work of the left heart by increasing the arterial resistance indicate that the left ventricle was relatively little affected. It was still capable of additional work at a time when an increase in venous blood supply led to a marked rise in pulmonary pressure so that lung edema was hastened and it became difficult or impossible to increase venous inflow.

The effect of the toxin does not occur quickly; rather, a latent period of considerable duration elapses before definite changes in right atrial pressure, in pulmonary pressure, or in competence become noticeable. This places these toxin effects in a group of delayed reactions characteristic of various types of other pharmacological agents, for instance, the cardiac glycosides and the thyroid hormone. One has to assume, in these instances, that the substance itself has to enter into or initiate a chain of reactions requiring considerable time before the characteristic effect eventually occurs. Since the toxin appears to be protein in nature, the question may be raised as to whether it may not be an enzyme. The identification of the $\mathrm{Cl}$. welchii alpha toxin as a lecithinase (7) provides the best example of a bacterial toxin which is enzymic in nature.

The experiments appear to indicate that $7 \mathrm{ml}$. of antitoxin was able to afford a considerable degree of protection against the toxic effect of 25,000 MLD of toxin irrespective of whether the antitoxin was administered prior to the toxin or 17 minutes after the toxin. Protective action was also present in the experiments in which injection of antitoxin preceded the administration of 50,000 MLD of toxin. Of the 4 experiments in which the antitoxin followed 15 minutes after the dose of 50,000 MLD of toxin, no protection could be seen in 2; severe lung edema developed in approximately the same period of time as in the experiments without antitoxin. In the 2 other experiments it is possible that some delay in the onset of pulmonary changes may have been caused by the antitoxin.

Protection against the action of 50,000 MLD of toxin was observed in the 3 experiments in which the heart and lungs or the blood used was obtained from immunized animals. While it is not possible to say that all immunized blood was removed from the H.L.P. of Experiment 16, the amount of blood-immune bodies must have been greatly reduced by replacing the blood twice with blood from a non-immunized animal. However, this experiment is not a definite proof that tissueimmune bodies are sufficient to counteract the toxin action even if the blood is not immunized. On the other hand, immunized blood alone appears to give protection (Experiment 17).

\section{SUM MARY}

1. In the heart-lung preparation of the dog, $\mathrm{Cl}$. oedematiens toxin produces pronounced loss of plasma and whole blood in the pulmonary circulation. This phenomenon is observed only after a definite latent period.

2. The effects on the heart are minimal in comparison, for the heart is capable of increased work 
at the time when the pulmonary circulation is greatly impaired.

3. Antitoxin counteracts the change in permeability of the pulmonary vessels if it is present in the system when toxin is given. It is less effective when given early in the latent period.

4. Active immunization markedly diminishes the toxic effects on the pulmonary circulation. In the immunized dog the antitoxin is definitely present in the circulating blood, and the evidence is suggestive of the supposition that it may be present in the heart and lung tissue.

\section{BIBLIOGRAPHY}

1. Aub, J. C., Zamecnik, P. C., and Nathanson, I. T., Physiologic action of Clostridium oedematiens
(Novyi) toxin in dogs. J. Clin. Invest., 1947, 26, 404.

2. Wiggers, C. J., The present status of the shock problem. Physiol. Rev., 1942, 22, 74.

3. Patterson, S. W., and Starling E. H., On the mechanical factors which determine the output of the ventricles. J. Physiol., 1914, 48, 357.

4. Krayer, O., and Mendez, R., Studies on veratrum alkaloids. I. The action of veratrine upon the isolated mammalian heart. J. Pharmacol. and Exper. Therap., 1942, 74, 350.

5. Krayer, O., Versuche am insuffizienten Herzen. Arch. f. exper. Path. u. Pharmakol., 1931, 162, 1.

6. Nathanson, I. T., Rubin, J., Aub, J. C., and Zamecnik, P. C., Unpublished data.

7. Macfarlane, M. G., and Knight, B. C. J. G., The biochemistry of bacterial toxins. I. The lecithinase activity of $\mathrm{Cl}$. welchii toxins. Biochem. J., 1941. 35,884 . 